\title{
A Multi-agent System Melting Particle Swarm Optimization and Cellular Automata for the Simulation of Kiln Landscape in Ancient JingDeZhen DongHe River Basin
}

\author{
Tao Liu ${ }^{1}$, Xuan Xiao ${ }^{2}$ and Donglan Ying ${ }^{3}$ \\ ${ }^{1,2}$ School of Information Engineering of Jing-De-Zhen Ceramic Institute, Jing-De- \\ Zhen 333403, China \\ ${ }^{3}$ Department of Foreign Language of Jing-De-Zhen Ceramic Institute,Jing-De-Zhen \\ 333403, China \\ 1tjdz@126.com, 289534804@qq.com, ${ }^{3} 10922475 @ q q . c o m$
}

\begin{abstract}
To reveal how the ancient kiln has evolved atong DongHe River Basin in Jingdezhen -Jiangxi Province of China, and further reflect the interaction of the political situation, the institutions and the natural environment, we create ancient virtual maps of study area and propose such constructs to unambiguously denote a integration system by combining the advantages of mutt-agents, PSO and CA in time and space. We apply the system to model a dynamic interaction environment and conduct a series of spatial analyses of the land-use pattern from 1271 to 1554. Compared with model PSO-CA, the simulation result of this new model is of richer changing hierarchy and can better reflect the whole process from the first to the last firing. Meantime, the index Moran's L of simulation using the hybrid method is much closer to the actual Moran's I, which can better reflect the interaction between political environment and natural environment of different dynasties with the lack of ancient GIS spatial data.
\end{abstract}

Keywords: Multi-agen Particle Swarm Optimization; Cellular Automata; Kiln; landscape evolution

\section{Introduction}

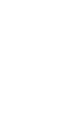

To understand the forming process of kilns landscape in ancient Jingdezhen Donghe river basin it is neessary to integrate both ecological and human porcelain making activities. While the ecological and sociological effects of land conversion for agricultural uses have been suded (Riebsame et al., 1994), the effects of land conversion for urbanization have also been studied (Jenerette \& Wu 2001), in addition, the effects of land conversion into grassland have been studied (Conant et al., 2001), but the effects of land conversion for ancient kiln landscape is less understood. In recent years, certain scholars have studied the figure's evolutionary development of Jingdezhen kilns (Lin et al., 2008), and some scholars have explored the developmental process of Jingdezhen porcelain making activities from geographical environment(Conant et al., 2001), however, the methods to deduce the process of ancient kilns are reported in the literature instead of utilizing computer technology.

In land-use change studies, cellular automata (CA) was the typical simulate tool of geographical landscape evolution and suitable for modeling processes where neighborhood 
influences. Studies have demonstrated that very complex behaviors and global patterns can be generated by applying some simple local rules in CA models(Couclelis 1997). Despite that original CA models have made great progress in the field, they have limitations in landscape simulation because they do not consider the influences of social and human factors explicitly(Benenson et al., 2002). Thus, the multi-agent system (MAS) for land-use change model is proposed to fill this gap. There are many experiments in using MAS to analyze and simulate complex systems(Chebeane \& Echalier 1999). Interactions between cellular and agent-based models allow considering land-use and land changes as a consequence of relations between biophysical and human dimensions - in space and time(Veldkamp \& Verburg 2004). The main advantage of using agent-based simulation lies in the possibility to model many diverse categories of agents.

In this paper, we divide agents into two types. They are the political agent and the artificial agent, and each agent represents the original actors present in the real-world. These agents will interact with each other by a series of actions, such as communications, cooperation and competitions(Liu et al., 2006), among which the decision mechanisms of the political agent is obtained from the historical facts, the decision mechanism of the artificial agent is assumed without rational and forward-looking expectations, at each time step, and an expected utility function is computed to choose between possible actions(Monticino et al., 2005). Actually, the decision mechanism of the artificial agent is a spatial optimization problem. For solving the special optimization problem, we use the particle in particle swarm optimization (PSO) to denote the agent of the kiln site. PSO is a stochastic optim Zation technique developed by Eberhart and Kennedy(Eberhart \& Kenned 1995). In PSQ a set of randomly generated solutions moves towards the optimal solution over a number of iterations by assimilating and sharing information among all members of the swarm Zhang \& Brorsen 2009). PSO has been shown to have the same ability to fine a global optimum as genetic algorithms, but it is able to find optimums faster than genetic algorithms (Hassan et al., 2005, Mouser \& Dunn 2005, Panda \& Padhy 2008). Existing PSO methods, however, cannot be directly applied to solving the special optimization problem. We improve PSO to solve the above problems under a dynamic environment with cooperative agents.

The objective of this essay is to create ancient virtual maps of study area and propose such constructs to unambiguously denote a multi-agent system integrating CA and PSO. We also compare the simulation under multi-agent to the simulation without multi-agent for simulating the evolution of Dorghe River Basin kiln landscape in Jingdezhen under lacking Geographic Information System and find the former can better reflect the whole process from the first to the last firing.

\section{The Virtual Map of Study Area in Ancient Time}

\subsection{The Study Area Selection}

ngdezhen City (east longitude $116^{\circ} 57^{\prime}--117^{\circ} 42^{\prime}$, north latitude $28^{\circ} 44^{\prime}--29^{\circ} 56^{\prime}$ ) is located in Northeast Jiangxi Province. From current archaeological excavations, Jingdezhen kiln landscape chiefly concentrates in the Nanhe and Donghe River Basin. This paper has the evolvement of kilns along Jingdezhen Donghe River Basin as the research object. The indicative region is shown in Figure 1. 


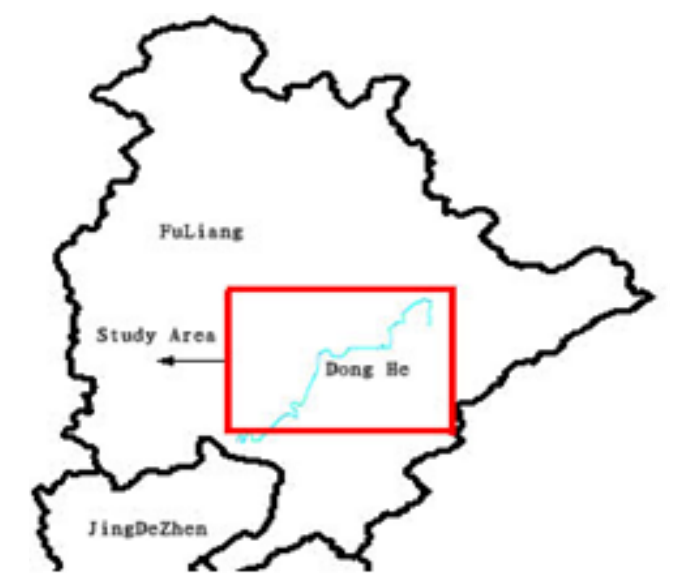

Figure 1. Study Area

\subsection{Virtual Map Building}

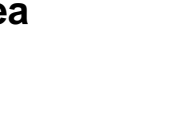

By consulting relevant literature, we know Jingdezhen hasn't made, Donghe diversion or moved the surrounding mountain over the years, which provides a basis for Donghe and the surrounding mountain land position in the study area. In the actual drawing process, by comparison with the screenshot of the study area via Google Maps, located DongHe and the surrounding mountain land can be firstly identified and then the land information except mountain and river is randomly generated. With this method, we can effectively explore the effect of the evolution of different geographical environment. This paper only shows one of them.

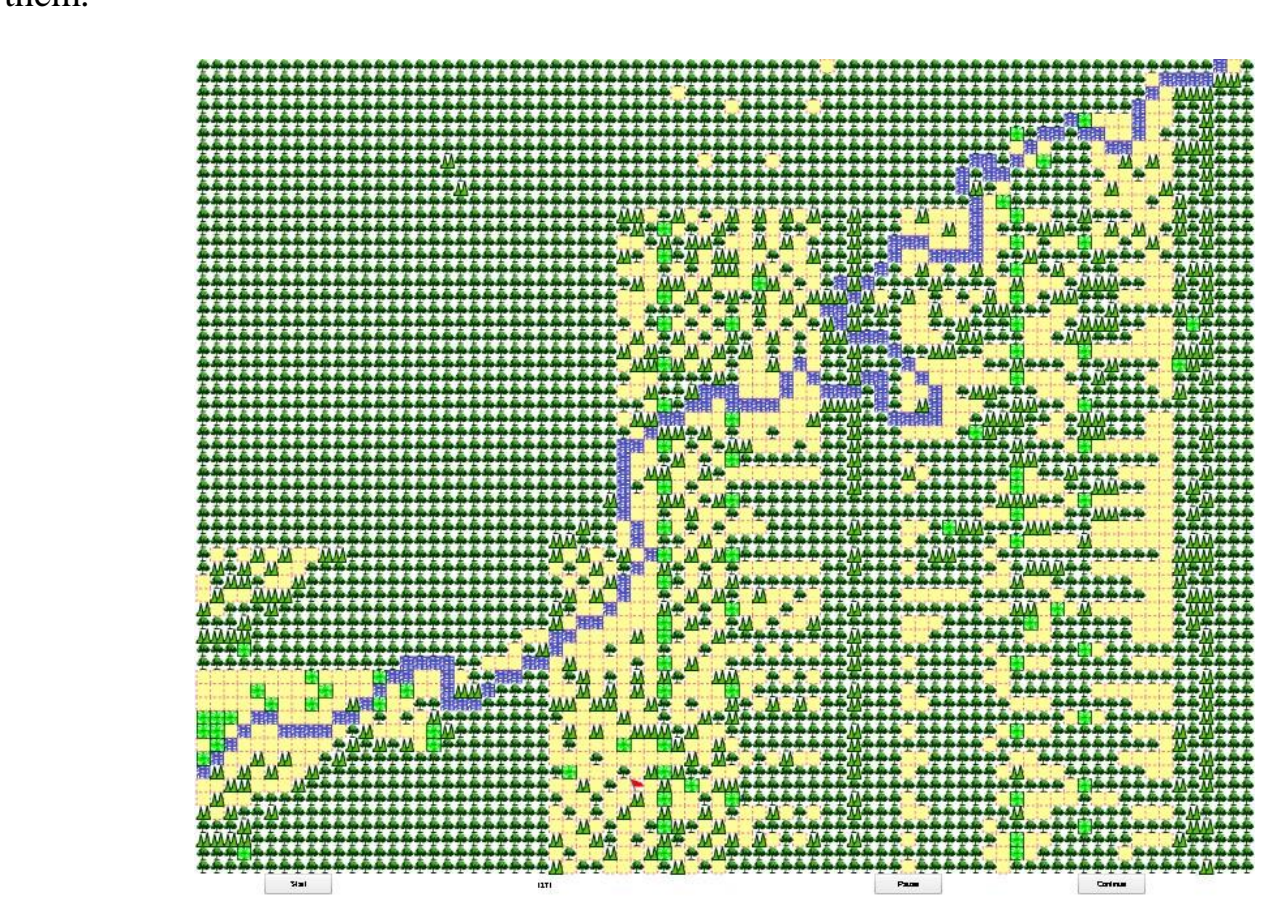

Figure 2. Grid Map of the Study Area 
In FlashCS3.0 software environment, the indicated study area in figure 1 can be divided into 60 rows and 78 columns grid data by use of ActionScript 3.0 language, and each grid land area is $20 * 20$ pixels. With the above method, we can get the two spatial dimensions grid map. The map is shown in Figure 2, in this map, the idle land, the farmland, the clay mine,

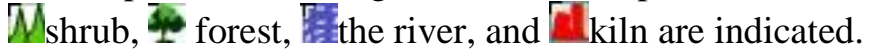

\section{Classification and Presentation of Multi-agent}

In this study, we use two types of agents to simulate the kiln site development in Jingdezhen Donghe river basin. They are the political agent and artificial agent.

\subsection{Artificial Agent}

In this study, the particle of PSO stands for artificial agent, namely kiln site agent, used for spatial optimization, which sparsely distributes and moves as time goes in space grid. For solving the special optimization problem, we improve the original PSO as follows:

3.1.1. Integer of Particle Position: For randomly generated particle in the initial state, its location must be a unit in the two-dimensional grid space, namely the values of the particle position are in the integer space. However, the original particle swarm/optimization is based on real number space, so integer of particle position becomes necessary. In the initial randomly generated number of particles, the number of rows 1 is in the value $[1,60]$, the number of columns $\mathrm{j}$ is in the value $[1,78]$ so the starting position is an integer value. Then make integer modifications to the particle swarm optimization algorithm speed formula (Equation 1) to get the speed of the next moment, and at last get a new integer position by position formula (Equation 2).

$$
\begin{aligned}
& V_{i j}^{t+1}=\operatorname{ceil}\left(\omega \times V_{i j}^{t}+c_{1} \times \text { rand } \times\left(\text { Pbest } t_{i j}-\mathcal{X}_{i j}^{t}\right)+c_{2} \times \text { rand } \times\left(\text { G best }_{g j}^{t}-X_{i j}^{t}\right)\right) \\
& X_{i j}^{t+1}=X_{i j}^{t}+V_{i j}^{t+1}
\end{aligned}
$$

Where $\mathrm{X}$ and $\mathrm{V}$ respectively show the $\mathrm{i}$-th particle's position and velocity, $\mathrm{w}$ is inertia weight, $c 1, c 2$ is the acceleration factor, $t 1, r 2$ is two random number between $[0,1]$, subscript $\mathrm{j}$ is particle's $\mathrm{j}$-thdimension, $t$ is iterations, $\mathrm{i}$ is $\mathrm{i}$-th particle, ceil is integer function.

3.1.2. Definition of Fitness Function: In ancient times, Jingdezhen Ceramic production used wood as fuel, and finished products were transported through rivers, so the development of a land into a kiln to a large extent was affected by the distance from the river, the distance from the mountain. According to this characteristic, the fitness function of particle swarm optimization algorithm is defined as Equation 3.

$$
f(x, y)=\frac{1}{N} \sum_{i=1}^{2}\left(\left(x-x_{i}\right)^{2}+\left(y-y_{i}\right)^{2}\right)
$$

Among them, $\left(x_{1}, y_{1}\right)$ is the nearest river coordinates away from the current grid, $\left(x_{2}, y_{2}\right)$ is nearest mountain coordinates away from the current grid, $(x, y)$ is current grid coordinates. value of $N$ is 2 , when none of the river distance, mountain distance, $N$ is 2 ; when one of them is zero, $N$ is 1.In addition, the nearer distance of the nearest clay mine coordinates from the current grid is better. 


\subsection{Political Agent}

In this research, political agent consists of political situation and institution, on behalf of political situation and institution in the given dynasty, which is of no spatial attribute, and only changes its political attributes as time goes. Because this research spanned different dynasties, the stability of political situation and decision-making institution by governments of different dynasties play a decisive role in the process of kiln evolvement. At the same time, changes in ceramic production also influence the government decision-making institution. In this model application, we divided the research into the following four stages in order to better describe political attributes:

\section{A.D.1271-A.D.1349}

In this period, Yuan dynasty was established and gradually became stable, so jits politícal attribute is defined stable. Moreover, the rulers of Yuan dynasty attached great importance to handicraft industry, so they not only improved the status of folk ceramic craftsmen, set up Fuliang Ceramic Bureau in Jingdezhen, specially supervising ceramic production for government, but also fired ceramics of Council glaze by way of binary formulation, so that the production and quality were both improved. Under the influence, the production of folk kilns which mainly processed ceramic materials in Donghe River Basin developed greatly. The development of ceramic-making scale made Fuliang more prosperous, attracting many people to migrate to Fuliang, which can be seen from "History of Fuliang County" of "History of Yuan Dynasty"---the population of Fuliang county increased from 121,507 in A.D. 1215 to 192,140 in A.D. 1290.

\section{A.D.1350-A.D.1362}

From the reference, we canknow the leader of Red Army-Xiang pulv conquered Fuliang in A.D.1350, and this county was at war until the year of 1357.In A.D.1360, Li Yong guarded Fuliang and the political situation there grew gradually stable. The production of ceramics began to recover in AD.1362, so we defined the political attribute in this period to be wartime, and the ceramic production in this period was basically stagnant.

\section{A.D.1363-A.D. 401}

This period of time cam be divided into two parts: the former part is from A.D.1363 to A.D.1367 in late Yuan cynasty, while the latter part is from A.D.1368 to 1401 in early Ming dynasty, during which Fuliang was under the administration of Zhu Yuanzhang, so we defined the politica attribute in this period to tending towards stability. During this period, the taboo of "royal clay" was broken, so many official craftsmen lived with common people, and folk kilns had access to the royal clay of high quality, leading to larger-scale production of ceramics.

4. A.D.1402-A.D. 1554

During this period, Ming dynasty was established and the society was stable, furthermore Ming dynasty paid great attention to the development of handicraft industry. In 1402 the government set "Royal Kiln" factory, specially firing ceramics for the royal family and monopolying ceramic clay of good quality as "official clay", which can only be used by "Royal Kiln" factory. Under this system, the production of folk kilns in Donghe River Basin faded gradually. 


\section{A Multi-agent System Melting PSO and CA}

Cellular Automata general includes four elements of the unit, state, close range and conversion rules(Liu et al 2008). The four-tuple formula is $A=\left(L_{d}, S, N, F\right)$, among which, $\mathrm{L}$ represents the grid space divided by a rule, namely a cellular, $\mathrm{d}$ is the dimension of $\mathrm{L}$, usually equal to 1 or $2, \mathrm{~S}$ means the state of each cell and is a discrete finite set, $\mathrm{N}$ is neighbors cellular, $\mathrm{F}$ is the conversion rules, and is the core part of $\mathrm{CA}$. The state transition of each cell from the time $\mathrm{T}$ to $\mathrm{T}+1$ is determined by the conversion rules.

To facilitate research, this article looks on the study area as an island, the division of the $\mathrm{CA}$ of the square grid space as an experimental basis, using the Moore neighborhood, fixed value boundary. Suppose map _maps is a $60 \times 78$ grid map, each grid cell is $20 * 20$ pixels, cellular space $L=\left\{-\right.$ maps $\left._{i, j} \mid 1 \leq i \leq 60,1 \leq j \leq 78\right\}$, dimension $d=2$, and state sets $s=\{0,1,2,3,4,5,6\}$, number 0-6 respectively stands for idle land, river, mountan, shrub, farmland, porcelain corresponding productive land(kiln), clay mine Center Cellular _maps[i][j] has eight neighbors cell. The conversion rules fare described as follows:

1. Artificial agent constantly moves in $60 \times 78$ grid space to determine the location of candidate target grids, making the average distance from candidate target distance grid to the clay mine, DongHe and the surrounding mountain is the minimum. These regions will be developed into candidate land of the kiln.

2. To analyze the suitable conditions of the candidate land, if the suitable conditions are satisfactory, it can evolve into the kiln. Otherwise, it carr. The adaptation function (Equation 4) will return $[0,1]$, such as if the land itself is river or mountain, the return value is 0 , other land is impacted by political agent. Eand suitability conditions function values are differently set in four periods. In the first stage, due to the influence of firing the ceramics of Council glaze, the dragon kiln is mainly used, while the gourd kiln is minor. Because the dragon kiln is created on the slope land, as a result set the return value is 0.7 if it is shrub, farmland is 0.4 , and idle land is 0.6 . In the second period, ceramic production is almost stagnated because of the war, so all the land suitability value is lower than that of the previous period. The return value of shrub is 0.2, farmland is 0.1 , and idle land is 0.2 . The third period ceramics production is of full recovery and rapid development, so all the land suitability value is supper than that of the previous period: the return value of shrub is 0.7 , farmland is 0.5 , and idle land is 0.8 . The political situation is most stable in all periods, institution attaches importance to food production, and the protection awareness of farmland is stronger, so the return value of farmland is 0.3 , and the value of other land equals the value in previous period.

$$
\operatorname{Con}(S \mid=\text { suitable })
$$

Among them, $S_{i j}^{t}$ represents the state of $(i, j)$ block at $t$ moment.

3. Whether a block can be developed into a kiln is affected by its own conditions as well as the surrounding neighbor cell, represented by the neighborhood function (Equation 5).

Because the ancient ceramic production needed a large number of kiln men and the traffic was not convenient at that time, kiln men could only perch on the local village. If village is in the neighborhood, the function value is 1 , if mountain and river is in the neighborhood, the function value is 1 , if mountain is in the neighborhood but river is not in, the function value is 0.6 ; if river is in the neighborhood but mountain is not in, the function value is 0.8 , if mountain and river is not in the neighborhood, the function value is 0 . 


$$
\Omega_{i j}^{t}=\frac{\sum_{3 \times 3} \operatorname{Con}\left(S_{i j}=\text { suitable }\right)}{3 \times 3-1}
$$

4. Whether a region can be developed into a kiln can be obtained by the formula 6 , and then set the probability threshold, if the result is greater than the probability threshold, it can evolve into the kiln. Otherwise, it can't.

$$
P_{i j}^{t}=\operatorname{Con}\left(S_{i j}^{t}=\text { suitable }\right) \times \Omega_{i j}^{t}
$$

5. Influenced by political agent, conversion probability threshold also set different values according to the four periods. The first period is 0.8 , the second period is $1.2,0.6$ is the third period, and the fourth period is 0.8 .

\section{Experimental Simulation and Analysis}

Simulation of the existing objective facts is the basic condition of judging whether a model is reasonable or not, however, the more important purpose of the model lies in predicting or deducing unknown facts. In this paper, we simulated land-use chânge respectively by using MA-PSO-CA and using PSO-CA, select two periods of simulation results in the Yuan dynasty and the Ming dynasty for comparison whep-other related factors are the same, and Table 1 shows the contrast results.

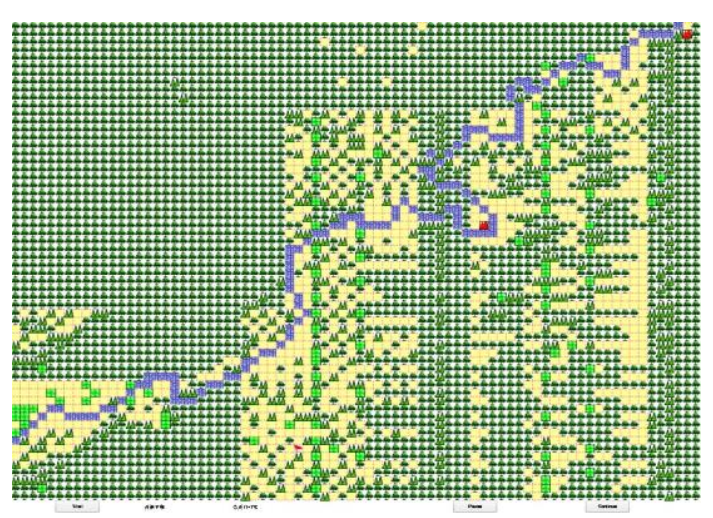

Figure 3. Simulation Result of MA-PSO-CA in Stage 1

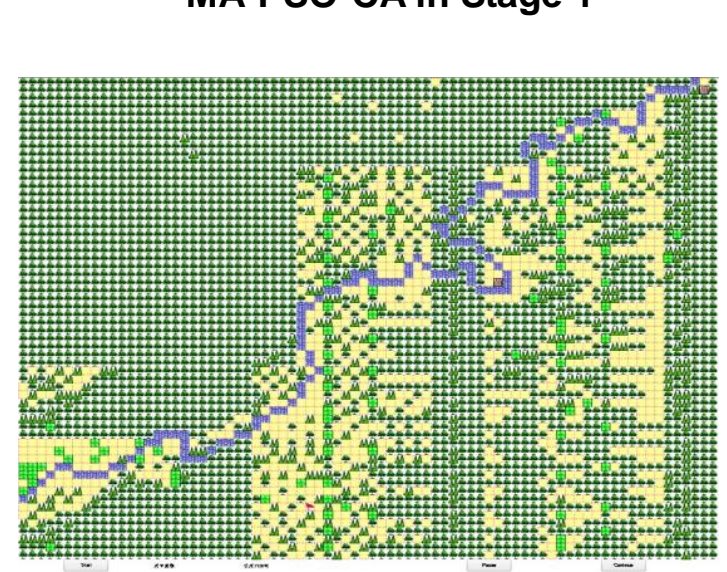

Figure 5. Simulation Result of MA-PSO-CA in Stage 2

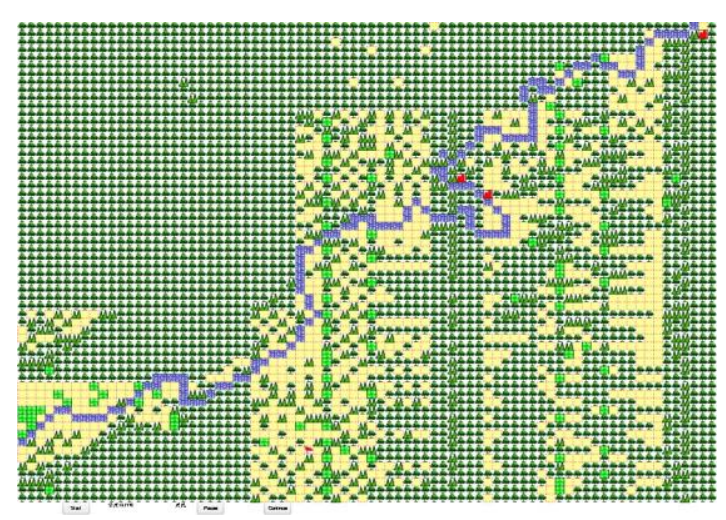

Figure 4. Simulation Result of PSO-CA in Stage 1

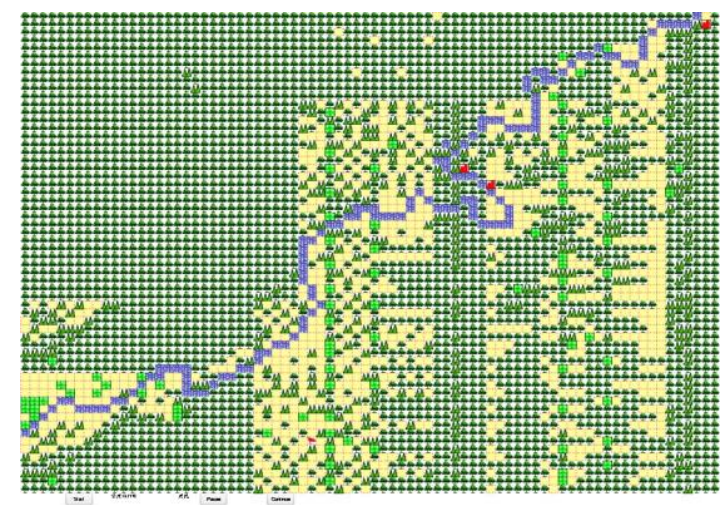

Figure 6. Simulation Result of PSO-CA in Stage 2 


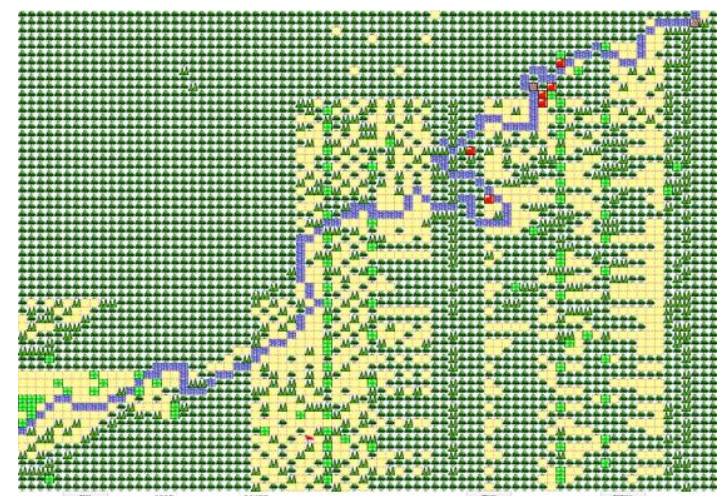

Figure 7. Simulation Result of MA-PSO-CA in Stage 3

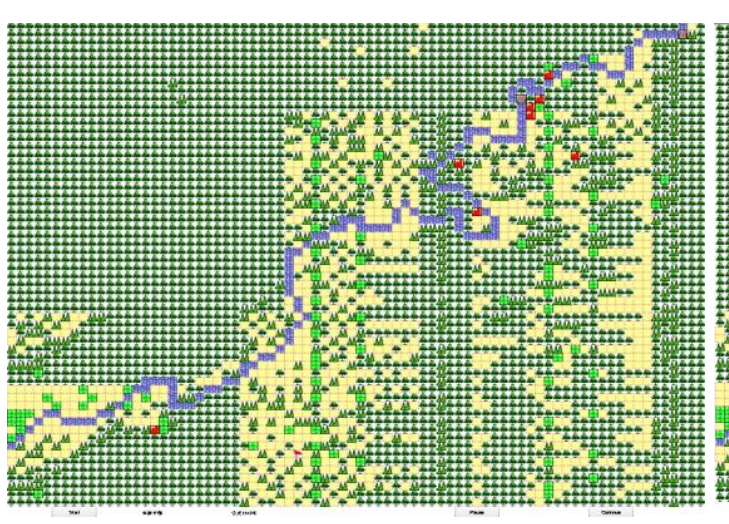

Figure 9.Simulation Result of MA-PSO-CA in Stage 4

Table 1. Simulation Results under Different Models

\begin{tabular}{|c|c|c|c|}
\hline \multirow{2}{*}{$\begin{array}{c}\text { research } \\
\text { stage }\end{array}$} & Qyears & \multicolumn{2}{c|}{ simulation results } \\
\cline { 3 - 4 } & A.D. 1271-A.D.1349 & MA-PSO-CA model & PSO-CA model \\
\hline stage 1 & A.D.1350-A.D.1362 & figure 3 & figure 4 \\
\hline stage 2 & A.D.1363-A.D.1401 & figure 7 & figure 6 \\
\hline stage 3 & A.D.1402-A.D.1554 & figure 9 & figure 10 \\
\hline stage 4 & &
\end{tabular}

At present, the model test methods are generally the point-by-point comparison and the overall comparison (Hashemi \& Meybodi 2009). Point-by-point comparison is to congruent the simulation results and the actual situation, and then compare and calculate its accuracy point by point; the overall comparison is concerned with the similarity between the simulated spatial pattern and the actual spatial pattern, often using Moran's I index contrast. Moran's I index is calculated based on the covariance relation of statistical correlation coefficient. Moran's I index is commonly used to describe the spatial autocorrelation, and its formula is:

$$
I=\frac{n}{\sum_{i=1}^{n} \sum_{j=1}^{n} W_{j i}} \times \frac{\sum_{i=1}^{n} \sum_{j=1}^{n} W_{i j}\left(x_{i}-\bar{x}\right)\left(x_{j}-\bar{x}\right)}{\sum_{i=1}^{n}\left(x_{i}-\bar{x}\right)^{2}}
$$


In the formula, $n$ is the number of spatial units involved in the analysis, $x_{i}$ and $x_{j}$ respectively stands for observations of an attribute feature in the spatial units $i$ and spatial unit $j, W_{i j}$ is the neighboring weight matrix of spatial units $i$ and $j$. If adjacent, $W_{i j}$ is 1 , if not adjacent $W_{i j}$ is 0 . In this paper, Moran's I index is used for model checking, and the compared results of the table 1 are programmed in Matlab7.0, as shown in Table 2.

Table 2. Moran's I Index Contrast

\begin{tabular}{|c|c|c|c|}
\hline \multirow{3}{*}{ years } & \multicolumn{3}{|c|}{ Moran' s I Index } \\
\hline & real & MA-PSO-CA model & PS0-CA model \\
\hline & value & simulate value & simulate $\mathrm{v}$ \\
\hline A. D. 1271-A. D. 1349 & 0.1392 & 0.1383 & 0.1395 \\
\hline A. D. 1350-A. D. 1362 & 0.1383 & 0.1383 & 0.1395 \\
\hline A. D. 1363-A. D. 1401 & 0.1296 & 0.1302 & \\
\hline A. D. $1402-$ A. D. 1554 & 0.1309 & 0.1310 & 1349 \\
\hline
\end{tabular}

As can be seen from Table 1 and Table 2, there have some investigates as follow:

1. In each study phase, simulating results from modelMA - PSQ-CA are better than those acquired from model PSO - CA, because the index Moran's I of model MA-PSO-CA is closer to the actual Moran's I.

2. The simulation of model MA-PSO-CA is of richer changing hierarchy, which not only reflects the evolving situation of different dynasties, but also shows the evolvement in different years of the same dynasty: while PSO-CA can only reflect the evolvement of different dynasties without showing the evolvement in different years. That is because multiagents have been introduced into model MA-PSO-CA on the basis of model PSO-CA, establishing political agents to reflect politrear decisive attribute in different dynasties and agents to show landscape evolvement of kilns. The interaction and information communication between these two kinds of agents help the model to modify the suitability of land and probability threshold dynamically, which better reflects the interaction between complex political actors and naturalenvironment.

3. Because of continuous evolvement, from the entire research phase, we can find that model MA-PSOCA can better reflect the whole process from the first to the last firing compared with model $B S O C A$, which shows changes of political environment in different dynasties can affectland use, and also bring the appearance, development, prosperity and extinction to ceramic production.

\section{Conclusion}

In this paper, we simulate a multi-agent system integrating PSO and CA by combining the advantages of multi-agents, PSO and CA in time and space, and simulate the evolvement of kilns along Jingdezhen Donghe River Basin from 1271 to 1554. Compared with that of model PSO-CA, the simulation result of this new model is of richer changing hierarchy and can better reflect the whole process from the first to the last firing due to the relation between agents and the environment can dynamically modify land suitability values and transition probability threshold. Furthermore, the index Moran's I of simulation is much closer to the actual Moran's I, which can better reflect the interaction between political environment and natural environment of different dynasties with the lack of ancient GIS spatial data. 


\section{Acknowledgments}

This research was supported by the grants from the National Natural Science Foundation of China (No. 41061020) and the Science and Technology Research Foundation of Education Bureau of Jiangxi Province, China (No. GJJ13642).

\section{References}

[1] Reynolds RG. Proceedings of the Third Annual Conference on Evolutionary Programming. World Scientific. 131-39. (1994)

[2] Jenerette GD, Wu J. Analysis and simulation of land-use change in the central Arizona-Phoenix region, USA. Landscape Ecology 16: 611-26. (2001)

[3] Benenson I, Omer I, Hatna E. Entity-based modeling of urban residential dynamics: the case of Yaffo, Tel Aviv. environment and Planning B 29: 491-512.(2002)

[4] Chebeane H, Echalier F. Towards the use of a multi-agents event based design to improve reactivity of production systems. Computers \& industrial engineering 37: 9-13. (1999)

[5] Conant RT, Paustian K, Elliott ET. Grassland management and conversion into grass land: effects on soil carbon. Ecological Applications 11: 343-55. (2001)

[6] Couclelis H. From cellular automata to urban models: new principles for model development and implementation. environment and Planning B 24: 165-74. (1997)

[7] Eberhart R, Kennedy J. Micro Machine and Human Science. MHS'95, Proceedings of the Sixth International Symposium on (1995): 39-43. IEEE

[8] Hashemi A, Meybodi M. Cellular PSO: A PSO for dynamic environments. Advances in Computation and Intelligence: 422-33. (2009)

[9] Hassan R, Cohanim B, De Weck O, Venter G. Proceedings of the 1st AIAA multidisciplinary design optimization specialist conference. (2005)

[10] Jenerette GD, Wu J. Analysis and simulation of land-use change in the central Arizona-Phoenix region, USA. Landscape Ecology 6.611-26. (2001)

[11] Lin L, Qing F, Heping W, Li J, Xiaoyong'P. STUDY OF THE FIGURE'S EVOLUTIONARY DEVELOPMENT OF JINGDEZHEN KUNS. China Ceramics 2: 022. (2008)

[12] Liu X, Li X, Anthony G-OY. Multi-agent systems for simulating spatial decision behaviors and land-use dynamics. Science in China Series D: Earth Sciences 49: 1184-94. (2006)

[13] Liu X, Li X, Liư L, He J, Ai B A bottom- up approach to discover transition rules of cellular automata using ant intelligence. International Journal of Geographical Information Science 22: 1247-69. (2008)

[14] Monticino M, Acevedo MCallicott B, Cogdill T. Proc. of the 5th Int. Conf. on Modelling, Simulation and Optirnization (MSO2005) of the International Association of Science and Technology for Development (ed. G. Tonella) 279-84. (2005)

[15] Mouser C, Dunn S Comparing genetic algorithms and particle swarm optimisation for an inverse problem exere se. ANZIAM Journal 46: C89--C101. (2005)

[16] Panda S, Padhy NP. Comparison of particle swarm optimization and genetic algorithm for FACTS-based controller design. Applied soft computing 8: 1418-27. (2008)

[17] Riebsame W, Parton W, Galvin K, Burke I, Bohren L, et al. Integrated modeling of land use and cover change. Bioscience: $350-56$. (1994)

[18] Shannon RE. Simulation Conference Proceedings, Winter (1998), 1: 7-14. IEEE.

[19] Veldkamp A, Verburg P. Modelling land use change and environmental impact. Journal of Environmental Management 72: 1-3. (2004)

[20] Zhang T, Brorsen BW. Particle swarm optimization algorithm for agent-based artificial markets. Computational Economics 34: 399-417. (2009) 


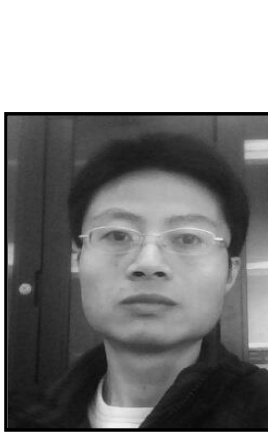

\section{Authors}

Tao Liu received his B.S. and M.S. degrees in Mathematics from South-central University for nationalities, Wuhan, China, in 1999 and Jingdezhen Ceramic Institute, Jingdezhen, China, in 2007, respectively. $\mathrm{He}$ is currently an associate professor in the Department of Computer, Jingdezhen Ceramic Institute, Jingdezhen, China. His research interests include evolutionary algorithms and its applications in the geographic landscape, and data mining.

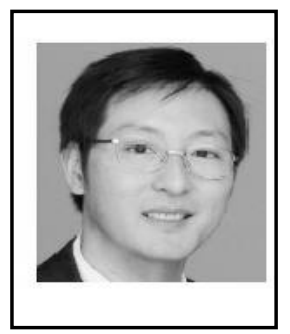

Xuan Xiao received his B.S. degrees in Television from Nanchang University, Nanchang, China, in 1991 and college of machime of Tianjing University, Tianjing, China, in 2002, respectively. And his PhD degree in control theory and control engineering from the Institute of information of Donghua university, Shanghai, China, in 2006.He is currently a professor in the Department of Machine and Electron, Jingdezhen Ceramic Institute, Jingdezhen, China. His research interests include pattern recognition, bioinformatics, and sensory evaluation.
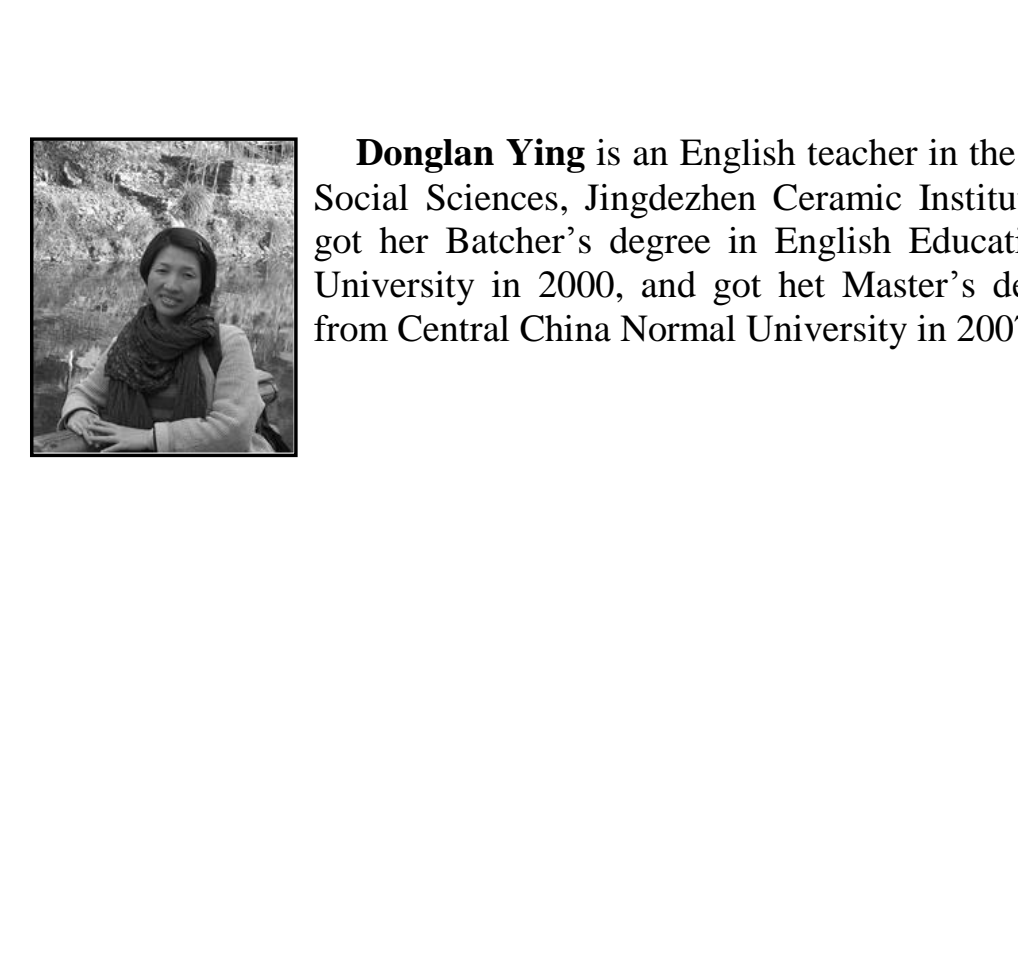
International Journal of Smart Home

Vol.8, No.5 (2014)

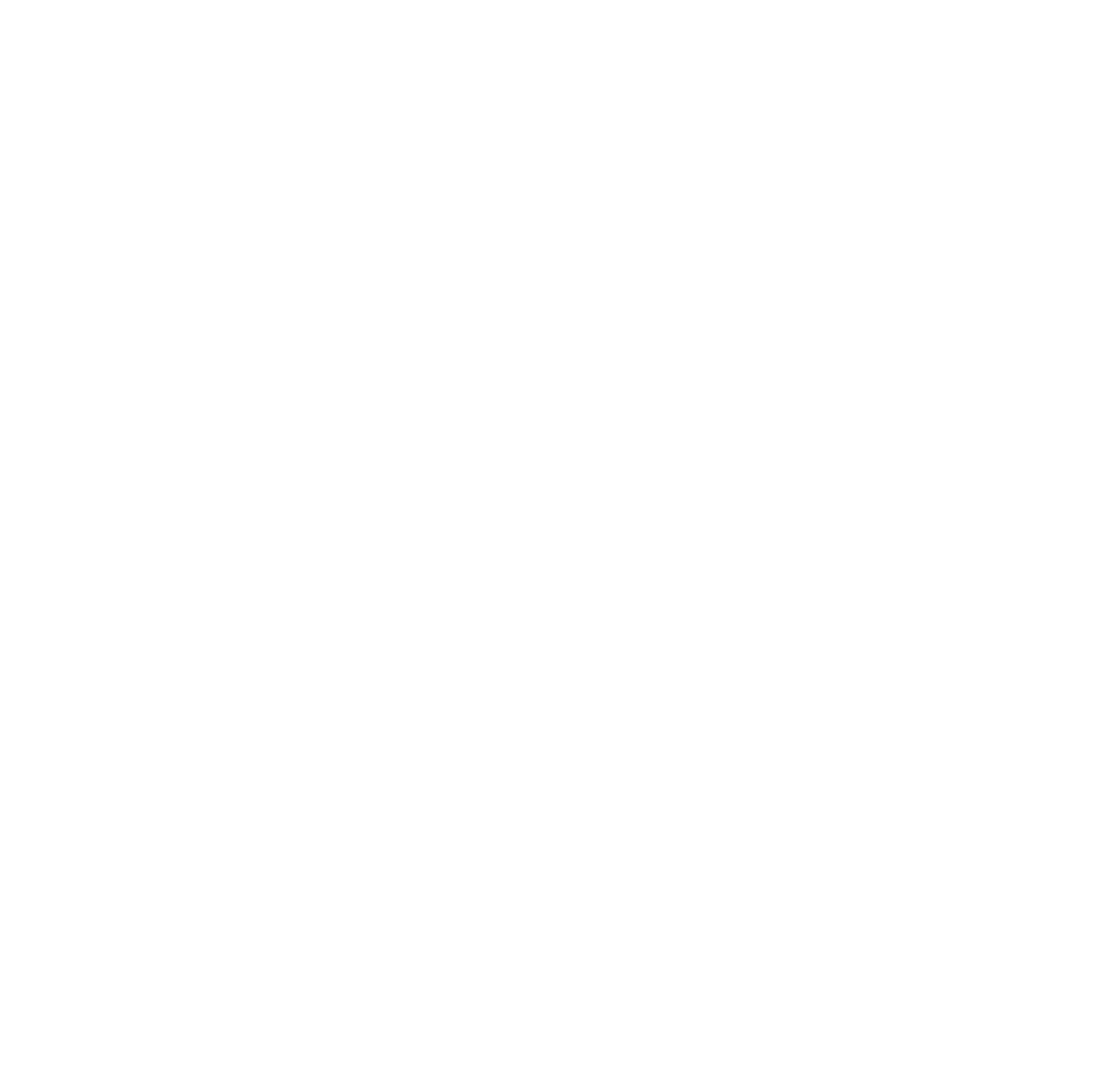

